\title{
To Assess the Knowledge and Awareness of Interns Regarding the Management of Tuberculosis as per Recent RNTCP (2017-2025) Guidelines - A Cross Sectional Study
}

\author{
Anamika Ajith (First Author), Undergraduate student, $2^{\text {nd }}$ year MBBS, Jawaharlal Nehru Medical College, Belagavi, Karnataka \\ Dr. Rekha Nayaka M.R (Correspondence Author), Associate Professor, Department of Pharmacology, \\ Jawaharlal Nehru Medical College, Belagavi, Karnataka
}

Abstract:

\section{$>$ Background:}

India has been engaged in Tuberculosis control activities for more than $\mathbf{5 0}$ years as India is the highest TB burdened country in the world. One such initiative is Revised National Tuberculosis Control Programme (RNTCP) which has been rechristened as National Tuberculosis Elimination Programme (NTEP). The change in name is in line with the larger goal of eliminating the disease by 2025 .

\section{$>$ Objective:}

The aim of this cross-sectional study is to assess the knowledge and awareness of interns regarding the management of tuberculosis as per recent RNTCP guidelines.

\section{$>$ Materials \& Methods:}

A structured questionnaire was provided to 111 interns to be filled in a stipulated time. The data collected was analyzed using descriptive statistical parameters and expressed in percentage.

\section{$>$ Result:}

Out of a total of 111 interns, $48(43.24 \%)$ were males and $63(56.75 \%)$ were females. Good knowledge was seen among the interns regarding the cardinal symptoms of TB as well as definition of MDR-TB. $92.79 \%$ of the participants responded rightly about two sputum samples being taken for diagnosis of TB. Only $76.57 \%$ of interns knew the principle of treatment of TB as daily administration of fixed-dose combination of first-line anti-tubercular drugs as per appropriate weight bands and $61.27 \%$ of interns were unfamiliar of chemoprophylaxis of tuberculosis according to the recent RNTCP guidelines. Only $71.17 \%$ of the participants were updated about the follow-up procedure according to new guidelines. But only $36.93 \%$ of participants could answer Cotrimoxazole as the effective drug used in HIV-TB co-infection apart from routine TB drugs to reduce mortality.

\section{$>$ Conclusion:}

This survey is providing valuable information that there is deficiency of knowledge among the interns regarding management of tuberculosis according to recent RNTCP guidelines which can lead to treatment failure and thereby causing a hindrance to elimination of TB from our country by 2025 .

Keywords:- Interns, Knowledge, Management, RNTCP, Recent guidelines, Tuberculosis.

\section{INTRODUCTION}

Tuberculosis is one of the most common infectious disease and one among the top 10 causes of death worldwide from a single infectious agent. Nearly 10.0 million people fell ill with TB in 2018. ${ }^{[1]}$ According to the report released by World Health Organisation in 2019, India accounted for $27 \%$ of the world total TB cases. The emergence of resistance to anti-tubercular drugs has also become a significant public health problem globally and particularly in India. India had $27 \%$ of a total 1, 30,000 Multi Drug Resistant/ Rifampicin Resistant [MDR/RR] TB cases.

To combat the menace of $\mathrm{TB}$ which has been a devastating disease of all times, Ministry of Health and Family Welfare, Government of India launched The Revised National Tuberculosis Control Programme [RNTCP], based on the internationally recommended Directly Observed Treatment Short Course [DOTS] strategy. The goal of TB control programme is to decrease mortality and morbidity due to TB and cut transmission of infection until TB ceases to be a major public health problem in India ${ }^{[2]}$.

The objectives of RNTCP (1997) were to achieve at least $85 \%$ cure rate among the new smear-positive cases initiated on treatment and thereafter a case detection rate of at least $70 \%$ of such cases [3]. Currently, RNTCP (20172025 ) is reinforced with four strategic pillars of DETECTTREAT-PREVENT-BUILD [DTPB] under National Strategic Plan for moving towards TB elimination by $2025^{[4]}$. Few other latest initiatives include Private Sector Engagement, Introduction of newer drugs like Bedaquline, Delamanid; Nutritional Support etc. ${ }^{[5]}$ so that onward 
transmission of the disease can be curtailed. In addition to the above mentioned, WHO member states at the World Health Assembly 2014 has adopted "The End TB" strategy and its overall target is to 'End the Global TB Epidemic' by $2035^{[6,7]}$.

All the guidelines and strategies are being implemented and practised by the health care professionals. A substantial evidence for this is that the tuberculosis incidence rate in India has decreased by almost 50,000 patients over the past one year [In 2017 India had 27.4 lakh TB patients which came down to 26.9 lakh in 2018] ${ }^{[1]}$.

Hence, considering the importance of these approaches in the regulation of the disease and as interns are the budding health care professionals who are involved in management of tuberculosis as per RNTCP guidelines, this study is planned to assess their level of knowledge regarding the management of tuberculosis as per recent RNTCP guidelines. The results of this study will also show interns' awareness and their role in achieving the aim of TB elimination by 2025 .

\section{MATERIALS \& METHODS}

\section{Study design: A Cross-sectional study}

Source of Data:

Medical interns of KLES Dr. Prabhakar Kore Tertiary Care Charitable Hospital, Belagavi, Karnataka.

\section{Study Duration:}

Data collection, analysis and report preparation was done in duration of 2 months.

\section{Sample Size:}

Formula used for sample size calculation is

$$
n=\frac{p(1-p) Z \alpha / 2}{E^{2}}
$$

$\mathbf{n}$ is the sample size required, $\mathbf{p}$ is the proportion or prevalence, $\mathbf{E}$ is the absolute error, $\mathbf{Z}$ is the value corresponding to level of confidence required.

By assuming 50\% of total interns has good knowledge about the management of tuberculosis i.e.; $\mathrm{p}=0.5$. The Absolute error is taken as $5 \%$ with $95 \%$ confidence; the sample size will be,

$$
\begin{gathered}
n=\frac{0.5 \times(1-0.5) \times(1.96)^{2}}{(0.05)^{2}} \\
n=384.16 \approx 384
\end{gathered}
$$

Since the population is finite, the adjusted sample size $(n$ ') is given by

$$
n^{\prime}=\frac{n}{1+\frac{n-1}{N}}
$$

Where $\mathrm{n}$ sample size for large population; $\mathrm{N}$ is the finite population size $(\mathrm{N}=200)^{*}$.

$$
\begin{aligned}
& n^{\prime}=\frac{384}{1+\frac{384-1}{200}} \\
& n=131.73 \approx \mathbf{1 3 2}
\end{aligned}
$$
author.

Note:* $\mathrm{N}$ is taken as per the information given by the

If we consider $\mathrm{p}=0.2$ then the adjusted sample size will be 111 .

Hence this cross-sectional study was conducted among 111 participants, who are interns in KLES Dr. Prabhakar Kore Charitable Hospital, Belagavi, Karnataka.

\section{$>$ Method of collection of data:}

Participants were explained about the purpose of the study. Following the proposed methodology of the study, the interns were provided with a structured questionnaire. The questionnaire contained nearly 25 close-ended questions to assess every aspect of knowledge and awareness of interns regarding the management of tuberculosis as per the recent RNTCP guidelines. The questionnaire was pre-validated in the presence of subject experts. Pilot testing was done on 5 interns who were asked to tell regarding the content, consistency and clarity of the questionnaire. Necessary modifications were made as per the feedback given by the interns.

Data Collection: After obtaining approval from Institutional Ethics Committee, the interns who were willing to voluntarily participate in the study were given the questionnaire and to be filled anonymously within a stipulated time. Filling this questionnaire was taken as consent to participate. Confidentiality of the information was assured to the participants.

Data Analysis: After obtaining duly filled questionnaire from the participants, the collected data was analysed using descriptive statistical parameters and expressed in percentage.

\section{RESULTS}

Out of a total of 111 interns, $48(43.24 \%)$ were males and $63(56.75 \%)$ were females. All the participants were aware of recent RNTCP guidelines. Good knowledge was observed among the interns regarding the cardinal symptoms of TB as well as definition of MDR-TB. 92.79\% of the participants responded rightly about two sputum samples being taken for diagnosis of TB. Only $\mathbf{7 6 . 5 7 \%}$ of interns knew the principle of treatment of TB as daily administration of fixed-dose combination of first-line antitubercular drugs as per appropriate weight bands and $\mathbf{6 1 . 2 7 \%}$ of interns were unfamiliar of chemoprophylaxis of tuberculosis according to the recent RNTCP guidelines. Only $\mathbf{7 1 . 1 7 \%}$ of the participants were updated about the follow-up procedure according to new guidelines. But only 
ISSN No:-2456-2165

36.93\% of participants could answer the effective drug used in HIV-TB co-infection. Poor awareness was seen among the first contact physicians regarding the components of DOTS and Nikshay, which is a web based
TB notification portal. The questionnaire and the details are given in the table below:

Total number of participants, $\mathrm{N}=111$

\begin{tabular}{|c|c|c|}
\hline QUESTION & & PERCENTAGE \\
\hline $\begin{array}{l}\text { Q1. Are you aware of recent Revised National } \\
\text { Tuberculosis Control Programme (RNTCP) } 2017 \\
\text { guidelines used for TB management? } \\
\text { A] Yes } \\
\text { B] No }\end{array}$ & Yes $=111$ & $100 \%$ \\
\hline $\begin{array}{l}\text { Q2. What is your source of information about recent } \\
\text { RNTCP guidelines: } \\
\text { A] Sensitization programme by institution } \\
\text { B] Continuing Medical Education (CME) } \\
\text { C] Journals } \\
\text { D] Internet }\end{array}$ & $\begin{array}{c}\text { Sensitization programme by } \\
\text { institution }=17 \\
\text { CME }=20 \\
\text { Journals }=5 \\
\text { Internet }=69 \\
\end{array}$ & $\begin{array}{c}\text { Sensitization programme by } \\
\text { institution }=15.31 \% \\
\text { CME }=18.01 \% \\
\text { Journals }=4.5 \% \\
\text { Internet }=62.16 \%\end{array}$ \\
\hline QUESTION & $\begin{array}{l}\text { NO. OF PARTICIPANTS WITH } \\
\text { CORRECT RESPONSE }\end{array}$ & PERCENTAGE \\
\hline $\begin{array}{l}\text { Q3. Which of the following is not one of the } 5 \text { cardinal } \\
\text { symptoms of Pulmonary TB? } \\
\text { A] Cough and Fever > } 2 \text { weeks } \\
\text { B] Night sweats } \\
\text { C] Haemoptysis } \\
\text { D] Hematemesis }\end{array}$ & 111 & $100 \%$ \\
\hline $\begin{array}{l}\text { Q4. According to recent RNTCP recommendations, how } \\
\text { many sputum samples need to be collected and screened? } \\
\qquad \begin{array}{l}\text { A] } 3 \\
\text { B] } 2 \\
\text { C] } 1 \\
\text { D] } 4\end{array}\end{array}$ & 103 & $92.79 \%$ \\
\hline $\begin{array}{l}\text { Q5.How many treatment categories are there in DOTS? } \\
\qquad \begin{array}{l}\text { A] } 1 \\
\text { B] } 2 \\
\text { C] } 3 \\
\text { D] } 4\end{array}\end{array}$ & 108 & $97.29 \%$ \\
\hline $\begin{array}{c}\text { Q6.In DOTS, which group of patients are categorised into } \\
\text { category } 1 \text { and category2? } \\
\text { A] Category 1- New Patients } \\
\text { B] Category 2- New extra-pulmonary patients } \\
\text { C] Category 1- Previously treated patients } \\
\text { D] Category 1- Smear positive relapse patients }\end{array}$ & 89 & $80.18 \%$ \\
\hline $\begin{array}{l}\text { Q7. What is the duration of treatment in each category of } \\
\text { DOTS therapy? } \\
\begin{array}{l}\text { A] Category } 1=2 \text { months, Category } 2=6 \text { months } \\
\text { B] Category } 1=4 \text { months, Category } 2=6 \text { months } \\
\text { C] Category } 1=6 \text { months, Category } 2=8 \text { months } \\
\text { D] Category } 1=8 \text { months, Category } 2=8 \text { months }\end{array}\end{array}$ & 72 & $64.86 \%$ \\
\hline
\end{tabular}


ISSN No:-2456-2165

\begin{tabular}{|c|c|c|}
\hline 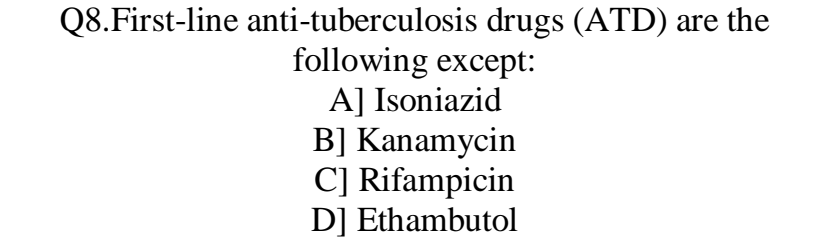 & 111 & $100 \%$ \\
\hline 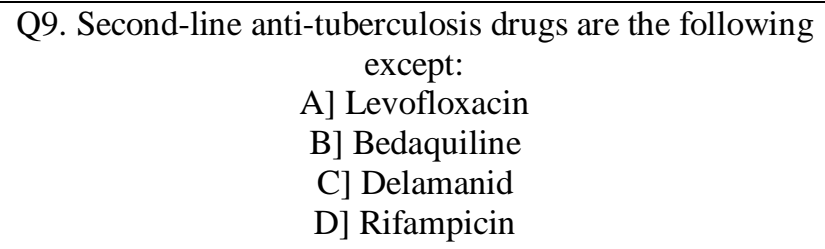 & 110 & $99.09 \%$ \\
\hline $\begin{array}{l}\text { Q10. Principle of treatment of TB according to recent } \\
\text { RNTCP } 2017 \text { guidelines is: } \\
\text { A] Daily administration of fixed-dose combination of } \\
\text { first-line ATD as per appropriate weight bands } \\
\text { B] Daily administration of fixed-dose combination of } \\
\text { first-line ATD not according to weight bands } \\
\text { C] Standard intermittent regimen } \\
\text { D] Drugs to be taken } 3 \text { times a week with first dose of the } \\
\text { week under supervision }\end{array}$ & 85 & $76.57 \%$ \\
\hline $\begin{array}{l}\text { Q11. Inj. Streptomycin is added in Intensive Phase for } 2 \\
\text { months in: } \\
\text { A] New drug sensitive patients } \\
\text { B] Previously treated drug sensitive patients } \\
\text { C] New drug resistant patients } \\
\text { D] Previously treated drug resistant patients }\end{array}$ & 74 & $66.66 \%$ \\
\hline $\begin{array}{l}\text { Q12. According to recent RNTCP } 2017 \text { guidelines: } \\
\text { A] Ethambutol is used in Continuation Phase of category } \\
2 \text { regimen only } \\
\text { B] Ethambutol is used in Continuation Phase of both } \\
\text { category } 1 \text { and } 2 \text { regimen } \\
\text { C] Pyrazinamide is used in Continuation Phase of } \\
\text { category } 2 \text { regimen only } \\
\text { D] Pyrazinamide is used in Continuation Phase of both } \\
\text { category } 1 \text { and } 2 \text { regimen }\end{array}$ & 91 & $81.98 \%$ \\
\hline $\begin{array}{l}\text { Q13. If the sputum smear is positive at the end of } \\
\text { Intensive Phase: } \\
\text { A] Intensive Phase is extended beyond } 2 \text { months } \\
\text { B] Intensive Phase is not extended beyond } 2 \text { months } \\
\text { C] Intensive Phase is extended beyond } 4 \text { months } \\
\text { D] None of the above }\end{array}$ & 83 & $74.77 \%$ \\
\hline $\begin{array}{l}\text { Q14. Follow-up of TB treatment according to new } \\
\text { RNTCP } 2017 \text { guidelines is/are done by: } \\
\text { A] Clinical follow-up } \\
\text { B] Follow-up by lab investigation } \\
\text { C] Both A and B } \\
\text { D] None of the above }\end{array}$ & 79 & $71.17 \%$ \\
\hline $\begin{array}{l}\text { Q15. Follow-up by lab investigation for Pulmonary TB } \\
\text { cases is done by: } \\
\text { A] Sputum smear examination at the end of Intensive } \\
\text { Phase and at the end of treatment. } \\
\text { B] Sputum smear examination to be done at } 2,4 \text { and } 6 \\
\text { months. }\end{array}$ & 77 & $69.36 \%$ \\
\hline
\end{tabular}


ISSN No:-2456-2165

\begin{tabular}{|c|c|c|}
\hline $\begin{array}{l}\text { C] Sputum smear examination to be done at } 3,5 \text { and } 8 \\
\text { months. } \\
\text { D] Sputum smear examination at the end of Intensive } \\
\text { Phase only. }\end{array}$ & & \\
\hline $\begin{array}{l}\text { Q16.Effective drug in TB-HIV co-infection apart from } \\
\text { routine TB drugs to reduce mortality: } \\
\text { A] Azithromycin } \\
\text { B] Cotrimoxazole } \\
\text { C] Ciprofloxacin } \\
\text { D] Ethambutol }\end{array}$ & 41 & $36.93 \%$ \\
\hline $\begin{array}{l}\text { Q17.Multi- Drug resistant tuberculosis (MDR-TB) is } \\
\text { defined as: } \\
\text { A] TB bacilli are resistant to Isoniazid \& Rifampicin with } \\
\text { or without resistance to others } \\
\text { B] Resistant to Isoniazid only } \\
\text { C] Resistant to Pyrazinamide } \\
\text { D1 None of the above }\end{array}$ & 111 & $100 \%$ \\
\hline $\begin{array}{l}\text { Q18. New or previously treated drug resistant case is to be } \\
\text { treated according to: } \\
\text { A] Regimen for new case } \\
\text { B] Regimen for previously treated case } \\
\text { C] Regimen based on DST } \\
\text { D] None of the above }\end{array}$ & 64 & $57.65 \%$ \\
\hline $\begin{array}{l}\text { Q19. In MDR- TB or Rifampicin resistance, a regimen } \\
\text { with at least } 5 \text { effective TB medicines during the Intensive } \\
\text { Phase is recommended as: } \\
\text { A] Pyrazinamide+ } 1 \text { from group A+ } 1 \text { from group B+ at } \\
\text { least } 2 \text { from group } C \\
\text { B] Pyrazinamide+ } 2 \text { from group A+ } 1 \text { from group B+ } 1 \\
\text { from group C } \\
\text { C] Ethambutol+ } 1 \text { from group A+ } 1 \text { from group B+ at } \\
\text { least } 2 \text { from group C } \\
\text { group C }\end{array}$ & 58 & $52.25 \%$ \\
\hline $\begin{array}{l}\text { Q20. Bedaquline, a new anti-TB is used in treatment of: } \\
\text { A] New case of Pulmonary TB } \\
\text { B] Multi-drug resistant TB (MDR-TB) } \\
\text { C] Both A and B } \\
\text { D] None of the above }\end{array}$ & 97 & $87.38 \%$ \\
\hline $\begin{array}{l}\text { Q21. Recent RNTCP policy on chemoprophylaxis is: } \\
\text { A] Give Isoniazid for } 6 \text { months to child }<6 \text { yrs. who are } \\
\text { contacts of TB patient after ruling out active TB. } \\
\text { B] Give Isoniazid for } 6 \text { months to child }<6 \text { yrs. who are } \\
\text { contacts of TB patient irrespective of BCG status after } \\
\text { ruling out active TB. } \\
\text { C] Give Isoniazid for } 3 \text { months to child }<6 \text { yrs. who are } \\
\text { contacts of TB patient, then do Purified Protein Derivative } \\
\text { (PPD) skin test. } \\
\text { D] All contacts of positive TB case receive } 6 \text { months of } \\
\text { Isoniazid }\end{array}$ & 43 & $38.73 \%$ \\
\hline $\begin{array}{l}\text { Q22. Which of the following is not a component of DOTS } \\
\text { strategy? } \\
\text { A] Standardized treatment, with no supervision and } \\
\text { patient support. } \\
\text { B] Political commitment with increased and sustained } \\
\text { financing. }\end{array}$ & 54 & $48.64 \%$ \\
\hline
\end{tabular}


ISSN No:-2456-2165

\begin{tabular}{|c|c|c|}
\hline $\begin{array}{l}\text { C] Case detection through quality-assured bacteriology. } \\
\text { D] An effective drug supply and management system. }\end{array}$ & & \\
\hline $\begin{array}{l}\text { Q23. The goal of National Strategic Plan (NSP) is: } \\
\text { A] To achieve a rapid decline in burden of TB, morbidity } \\
\text { and mortality while working towards elimination of TB in } \\
\text { India by } 2025 \text {. } \\
\text { B] Cure rate of at least } 60 \% \text { among newly detected smear } \\
\text { positive TB cases and case detection of at least } 50 \% \text { of } \\
\text { expected new smear positive PTB cases in a community. } \\
\text { C] To achieve a rapid decline in burden of TB, morbidity } \\
\text { and mortality while working towards elimination of TB in } \\
\text { India by } 2050 \text {. } \\
\text { D] None of the above }\end{array}$ & 88 & $79.27 \%$ \\
\hline $\begin{array}{l}\text { Q24. Which is the web based application for TB } \\
\text { monitoring \& notification: } \\
\text { A] Nischay } \\
\text { B] Nikshay } \\
\text { C] Nirbhay } \\
\text { D] e-DOTS }\end{array}$ & 78 & $70.27 \%$ \\
\hline $\begin{array}{l}\text { Q25. In January 2020, RNTCP got a change of name to: } \\
\text { A] National Tuberculosis Elimination Programme (NTEP) } \\
\text { B] Mission Indradhanush } \\
\text { B] None of the above } \\
\text { C] No change of name }\end{array}$ & 111 & $100 \%$ \\
\hline
\end{tabular}

\section{DISCUSSION}

In the present study, all the interns had good knowledge about the cardinal symptoms of pulmonary tuberculosis; first and second line drugs used in management of TB. But the participants did not have a thorough knowledge about the group of patients in each category in DOTS therapy and duration of each category. Only $64.86 \%$ of students could give the right response that category 1 is of 6 months and category 2 is of 8 months.

Lack of knowledge was observed as $\mathbf{2 3 . 4 3 \%}$ of the participants failed to give the exact principle of treatment of TB according to recent RNTCP guidelines as daily administration of fixed-dose combination of first-line antitubercular drugs as per appropriate weight bands. In the previous guidelines, follow-up sputum smear examination was to be done at 2,4 and 6 months for new cases but as per recent RNTCP policies sputum examination is done only at the end of intensive phase and at the end of treatment. Only $69.36 \%$ of the participants mentioned the change that had taken place.

All participants mentioned the correct definition of multi-drug resistant TB (MDR-TB) but only $\mathbf{5 2 . 2 5 \%}$ of them were able give the appropriate design of components with at least 5 effective TB medicines for treatment regimen in MDR-TB. Among the participants, only 48.64\% could correctly specify the components of DOTS. $\mathbf{2 9 . 7 3 \%}$ of the interns were unfamiliar of Nikshay, which is the web based application for TB monitoring and notification.

$62.16 \%$ of the budding doctors claimed that they acquired knowledge of recent RNTCP guidelines from internet and $18.01 \%$ obtained from CME.

Similar kinds of studies have been carried out in a number of institutions throughout India. A cross-sectional study on assessment of knowledge on management of pulmonary tuberculosis under RNTCP among graduating interns and post graduate students in RIMS Imphal, Manipur, India by Dr Bandi K Sangma et al ${ }^{[8]}$ showed that there is a lack of knowledge of TB signs and symptoms, diagnosis and treatment. In this study only $45 \%$ of the participants could correctly define new TB patients, relapse case, default, MDR-TB, XDR-TB and TB suspect. Only $12.1 \%$ had any kind of TB training.

The results of the study which assessed the awareness and knowledge of pulmonary tuberculosis and RNTCP guidelines among interns and post graduates at a tertiary care hospital in South India by Abdurehiman $\mathrm{T}$ et al ${ }^{[9]}$ revealed that enhancement of knowledge of tuberculosis and RNTCP guidelines among interns and post graduates is required and should be given special emphasis during their training. In this study, among 37 interns, 5.4\% had poor knowledge, $32.4 \%$ had fair knowledge and $62.2 \%$ had good knowledge regarding symptoms of TB. Among 53 PGs, $15.1 \%$ had fair knowledge and $75.5 \%$ had good knowledge. 
Only 9.4\% PGs mentioned all the symptoms and were categorized as excellent.

Another study on awareness of tuberculosis and RNTCP among undergraduate medical students and interns by Chennaveerappa P.K et al ${ }^{[10]}$ reported that most of the students were aware of the current situation of TB in India and objectives of RNTCP. A study done by Dinesh Mehta et al ${ }^{[11]}$ on the knowledge about tuberculosis management and national tuberculosis program among medical students in Haryana, India, revealed low level of knowledge among interns. The number of sputum specimen required for diagnosis under RNTCP was responded correctly by only $57 \%$ in their study.

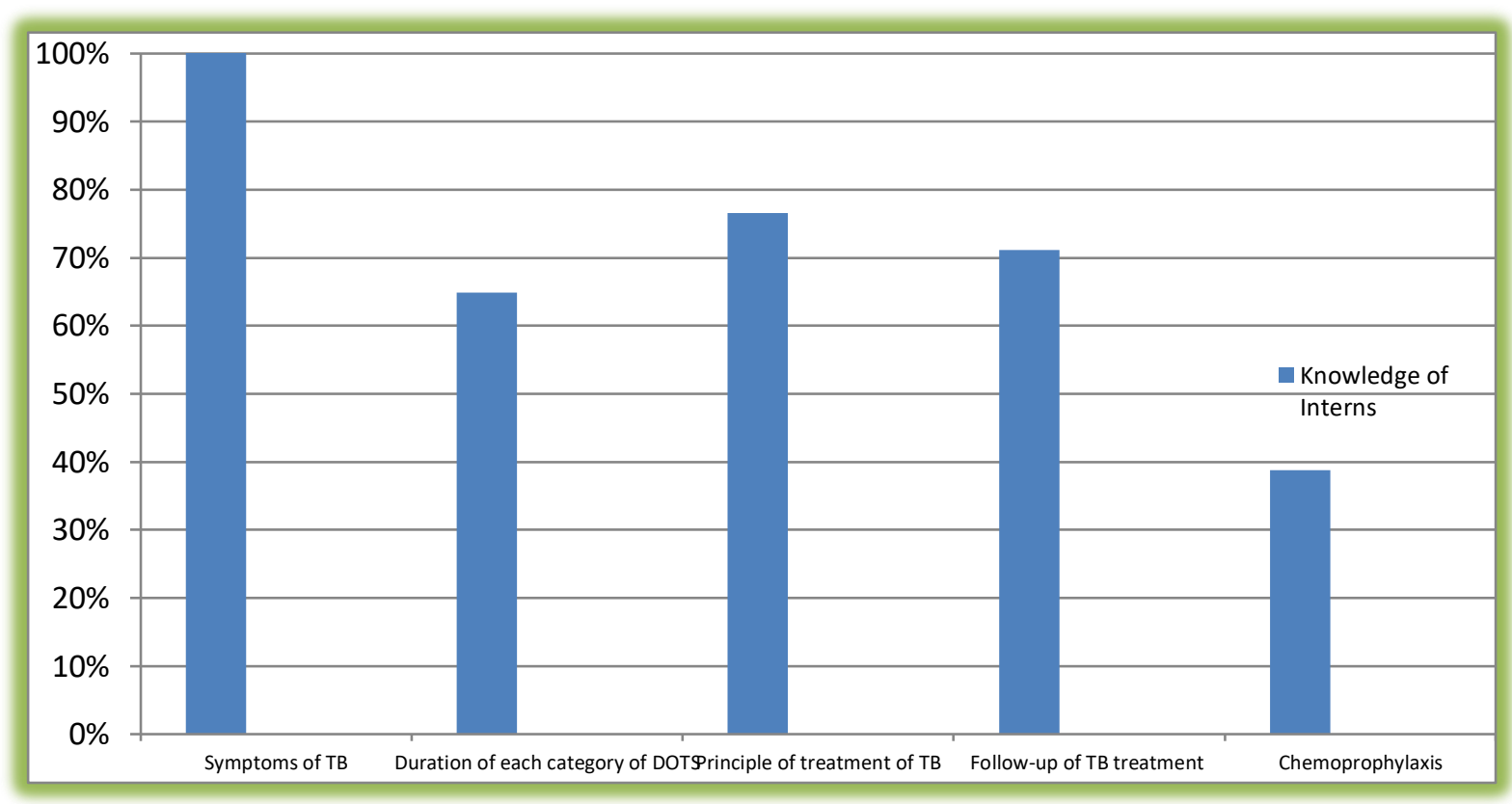

Graph 1: Depicts knowledge of interns regarding management of TB according to recent RNTCP guidelines.

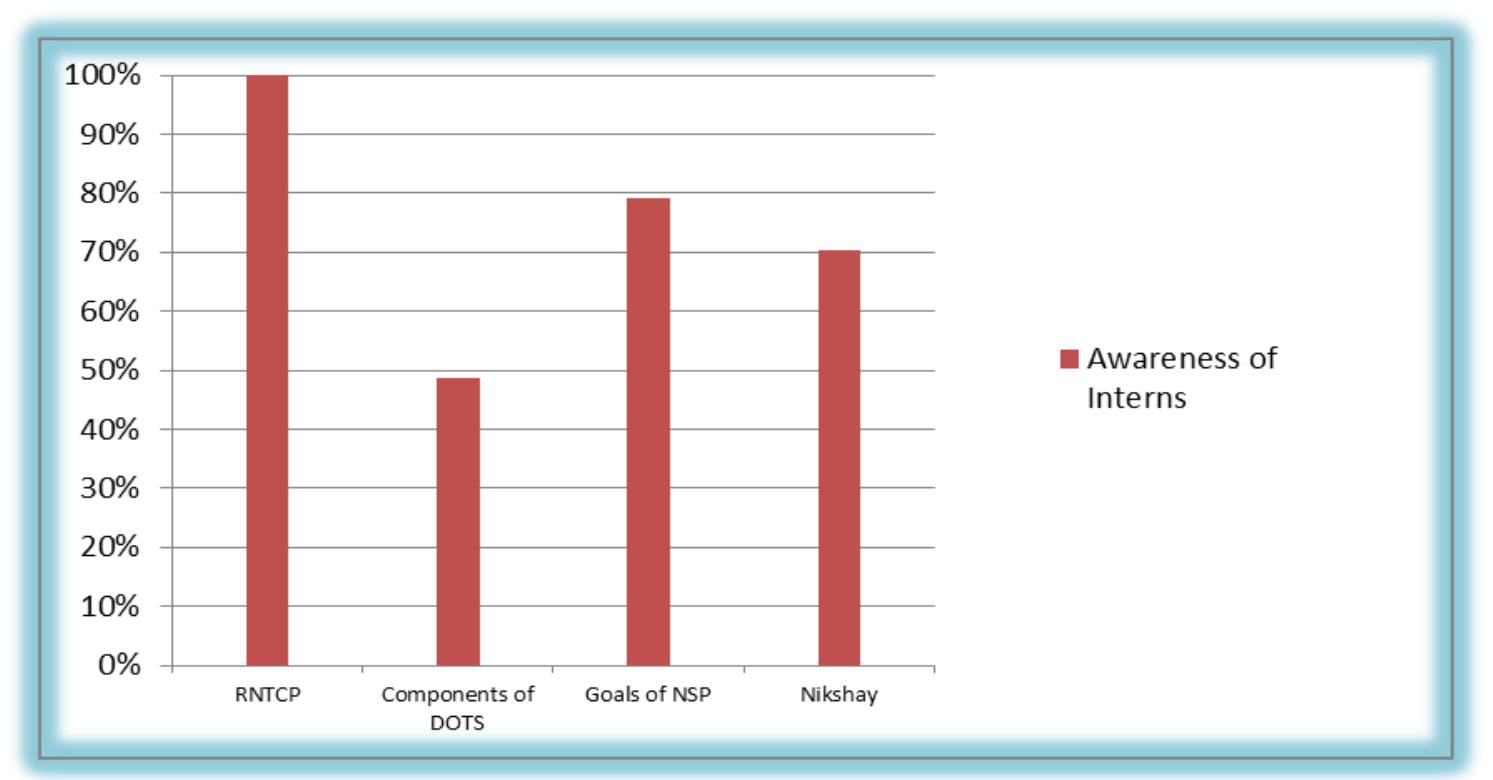

Graph 2: Depicts awareness of interns on management of TB according to recent RNTCP guidelines.

\section{CONCLUSION}

The study revealed inadequacies in the knowledge of recent RNTCP guidelines among interns. Interns being the sprouting doctors will be the caretakers of tomorrow's society. Hence it is mandatory for them to be aware and remain updated about RNTCP and National Strategic Plan (NSP) in order to achieve the goal of eliminating TB by
2025 in India. Inadequate management by health care professionals like interns can lead to treatment failure and drug resistance. This study availed us with an outline of interns' contribution in bringing down tubercular cases and also helped us to figure out if we are on track or are lagging in the path towards forging 'An India Free of TB'. As we can observe in the study, interns are well equipped with theoretical knowledge regarding TB and it is the practical 
side where they are lacking. Therefore, RNTCP training and DOTS/TB postings should be included in their curriculum and updated guidelines should be imparted to them on regular basis. Huge emphasis should be given along with their academics for appropriate management of tuberculosis under recent RNTCP policies in the form workshops or seminars, to empower them to be the most efficient in producing the desired result.

\section{REFERENCES}

[1]. Geneva: World Health Organisation. Global Tuberculosis Report 2019 by WHO. https://www.who.int/tb/publications/global_report/en/ (released on $17^{\text {th }}$ October 2019).

[2]. Kuldeep Singh Sachdeva, Ashok Kumar: New Vision for RNTCP: "Universal Access - Reaching the Unreached". The Indian Journal of Medical Research; Wolters Kluwer- Medknow Publications.

[3]. Chaudhari AD. Recent Changes in technical and operational guidelines for TB control programme in India-2016. A Paradigm Shift in Tuberculosis Control. J Assoc. Chest Physicians: 2017; 5:1-9.

[4]. Central TB Division, Director General Health Services, New Delhi- Achieving the goals of NSP: National Strategic Plan for TB elimination 2017-2025; 7.

[5]. https://www.nhp.gov.in/world-tuberculosis-day-pg/ World tuberculosis Day| National Health Portal of India.

[6]. Uplekar M, Weil D, Lonnroth K, Jarmillo E, Lienhardt C, Dias HM et al.WHO's New End TB Strategy. Lancet 2015; 385(9979): 1799-801 https://www.ncbi.nlm.nih.gov/pubmed/25814376 (accessed June 2019).

[7]. Implementing the End TB Strategy: the Essentials (WHO/HTM/TB/2015.31) Geneva: World Health Organisation; 2015. https://www.who.int/tb/publications/2015/The Essent ials to End TB/en/ (Accessed 28 June 2019).

[8]. Dr Bandi K Sangma, Dr Bhavya Shivalingaiah, Prof W Asoka Singh, Dr Lalfakzuala Renthlei, Dr Rosswel Sangma. 'Assessment of Knowledge on Management of Pulmonary Tuberculosis under RNTCP among graduating Interns and Post Graduate students in RIMS Imphal'. IOSR Journal of Nursing and Health Science; May - June 2017, PP 07-11. www.iosrjournals.org

[9]. Abdurehiman T, Krishnapriya Ramachandran, Arun Prasath R, Srinivasan R. " To Assess the Awareness and Knowledge of Pulmonary Tuberculosis and RNTCP guidelines among Interns and Post Graduates at a Tertiary care Hospital in South India'; Indian Journal of Research: Volume-7| Issue-1|January 2018.

[10]. Chennaveerappa P.K, Rajasekhar H.K, Jayashree Nagaral, Halesha B.R, Raghavendra Prasad K.U, Vinaykumar M.V, Nareshkumar M.N. " A Study on Awareness of Tuberculosis and RNTCP among Undergraduate Medical students and interns". Journal of Evolution of Medical and Dental Sciences 2014;
Vol.3, Issue 29, July 21; Page: 8115-8121, DOI: 10.14260/jemds/2014/3021.

[11]. Dinesh Mehta, Rishabh Bassi, Manjeet Singh, Chavi Mehta. To study the knowledge about tuberculosis management and national tuberculosis program among medical students and aspiring doctors in a Tertiary Medical College Hospital, Salem, Tamil Nadu. National Journal of research in Community Medicine. Vol.2. Issue 2. July-Sept.2013 (079-148) 